Jurnal Perikanan (2020) Volume 10. No. 2 : 195-204

DOI : https://doi.org/10.29303/jp.v10i2.215

\title{
IDENTIFIKASI JENIS ANGGUR LAUT (Caulerpa sp.) TELUK SEPANG KOTA BENGKULU
}

\section{IDENTIFICATION OF (Caulerpa sp.) SEPANG BAY AT BENGKULU CITY}

\author{
Ines Septiyaningrum ${ }^{1)}$, Maya Angraini Fajar Utami'), Yar Johan ${ }^{2)}$ \\ 1) Program Studi Ilmu Kelautan UNIB \\ *)alamat korespondensi: septia.ines26@gmail.com
}

\begin{abstract}
Abstrak
Penelitian ini bertujuan untuk mengidentifikasi jenis dan menganalisis kerapatan Anggur Laut di Pantai Teluk Sepang Kota Bengkulu. Penelitian ini dilaksanakan pada bulan Juli-Agustus 2020. Metode Penelitian menggunakan metode survei. Data yang dikumpulkan pada penelitian ini adalah data primer dan data sekunder. Kualitas air yang diamati seperti suhu yang diperoleh pada saat penelitian yaitu $30-31^{\circ} \mathrm{C}$, nilai $\mathrm{pH}$ yaitu 7,7-7,8, kecerahan berkisar antara 0,5-0,68 meter. Ditemukan 3 spesies Anggur laut di Pantai Teluk Sepang Kota Bengkulu dengan masing-masing nilai kerapatan relatif yaitu Caulerpa taxifolia $\left(46,6 \mathrm{ind} / \mathrm{m}^{2}\right)$, Caulerpa racemosa $\left(52,1 \mathrm{ind} / \mathrm{m}^{2}\right)$ dan Caulerpa lentillifera $\left(1,2 \mathrm{ind} / \mathrm{m}^{2}\right)$.
\end{abstract}

Kata Kunci : Caulerpa sp., Kualitas Air

\begin{abstract}
This study aims to identify the type and analyze the density of the Caulerpa sp. at Sepang Bay Beach, Bengkulu City. This research was conducted in July-August 2020. The research method used a survey method. The data collected in this study are primary data and secondary data. The observed water quality, such as the temperature obtained at the time of the study, was $30-31 \mathrm{oC}, \mathrm{pH}$ value was 7.7-7.8, brightness ranged from $0.5-$ 0.68 meters. Three species of Caulerpa sp. were found in Teluk Sepang Beach, Bengkulu City with each relative density value, namely Caulerpa taxifolia (46.6 ind / $\mathrm{m} 2)$, Caulerpa racemosa (52.1 ind / $\mathrm{m} 2)$ and Caulerpa lentillifera (1.2 ind / m2)).
\end{abstract}

Key words : Caulerpa sp., Water Quality

\section{PENDAHULUAN}

Rumput laut adalah sumber daya hayati yang telah dimanfaatkan masyarakat Indonesia sebagai mata pencaharian. Rumput laut merupakan tumbuhan tingkat rendah yang perawakannya relatif sulit dibedakan antar akar, batang dan daunnya. Keseluruhan tubuhnya disebut dengan talus. Rumput laut kaya akan serat, vitamin, dan mineral serta merupakan sumber antioksidan alami yang mudah didapat dan tersedia dalam jumlah cukup melimpah di alam (Ridhowati dan Asnani, 2016).

Salah satu jenis rumput laut yang potensial adalah Anggur Laut (Caulerpa sp.). Anggur Laut merupakan jenis alga 
hijau yang belum banyak dimanfaatkan dan termasuk dalam Feather Seaweed. Feather Seaweed dilaporkan sebagai makroalga yang dapat dimakan, mempunyai zat bioaktif seperti anti bakteri, anti jamur, anti tumor dan bisa digunakan untuk terapi tekanan darah tinggi dan gondok (Yangthong, 2009). Anggur Laut di Indonesia dikenal dengan sebutan Latoh (Jawa), Bulung Boni (Bali), Lawi-Lawi (Sulawesi), sedangkan di Jepang disebut umi budo. Caulerpa sp. memiliki bentuk dan rasanya menyerupai telur ikan caviar, sehingga dikenal sebagai "green caviar". Selain itu, makroalga ini juga disebut Anggur Laut karena bentuknya menyerupai anggur.

Anggur Laut merupakan jenis makroalga yang mampu tumbuh di seluruh paparan terumbu karang, disamping itu, faktor lingkungan seperti

\section{METODE PENELITIAN}

Penelitian ini dilaksanakan pada bulan Juli-Agustus 2020 di Pantai Teluk Sepang, Kota Bengkulu. Identifikasi suhu, $\mathrm{pH}$ (derajat keasaman), salinitas, dan kecerahan mempengaruhi keberadaan Caulerpa sp. (Kadi, 2000). Anggur Laut memiliki sebaran yang sangat luas di perairan laut. Anggur Laut mampu hidup pada lokasi-lokasi di perairan laut yang selalu tergenang air maupun lokasi yang mengalami kekeringan pada saat surut dan tergenang atau terkena air pada saat pasang.

Melihat pentingnya manfaat Anggur Laut serta kurangnya informasi mengenai penelitian terkait identifikasi jenis Anggur Laut di Pantai Teluk Kota Bengkulu, sehingga penulis tertarik untuk melakukan penelitian mengenai identifikasi jenis Anggur Laut. Diharapkan dengan adanya penelitian ini dapat memberikan informasi dan data mengenai jenis Anggur Laut di Pantai Teluk Sepang Kota Bengkulu.

jenis Anggur Laut dilakukan di Laboratorium Perikanan Universitas Bengkulu. Peta lokasi penelitian bisa dilihat pada Gambar 1.

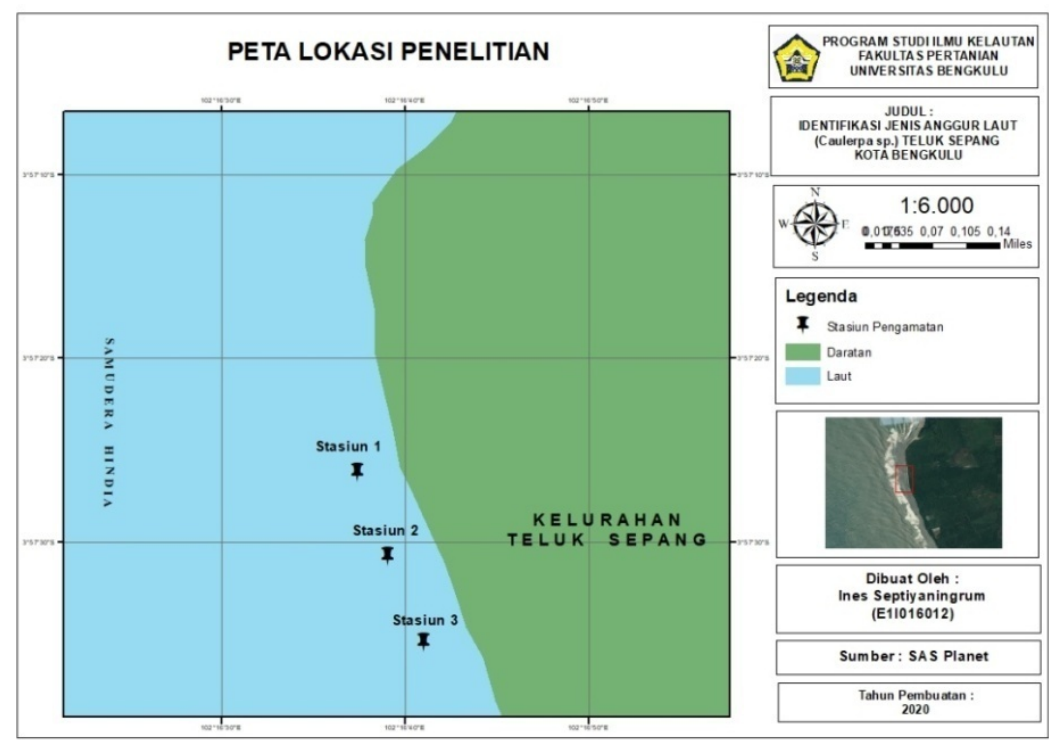

Gambar 1. Lokasi Penelitian 
Jurnal Perikanan (2020) Volume 10. No. 2 : 195-204

DOI : https://doi.org/10.29303/jp.v10i2.215

Alat-alat yang digunakan diantaranya adalah : kamera, Alat Tulis, Wadah sampel, Buku Identifikasi rumput laut, thermometer, Refraktometer, $\mathrm{pH}$ meter, GPS, Secchi

\section{Metode Pengumpulan Data}

Metode pengumpulan data menggunakan metode survei. Data yang dikumpulkan pada penelitian ini adalah data primer dan data sekunder. Data primer meliputi data kualitas perairan yang didapat secara langsung di lokasi penelitian maupun yang didapat dari pengukuran di laboratorium, sedangkan data sekunder merupakan data pendukung yang diperoleh dari literatur pendukung seperti buku identifikasi.

\section{Parameter Penelitian}

Pada lokasi pengambilan sampel Anggur Laut dilakukan pengukuran parameter perairan yang meliputi: suhu, salinitas, $\mathrm{pH}$ (derajat keasaman), dan kecerahan. Pengukuran parameter dilakukan secara langsung pada tiap stasiun yang telah ditentukan dengan tiga kali pengulangan pengukuran pada masing-masing stasiun.

Metode penentuan lokasi sampling pada penelitian ini adalah dengan menggunakan metode survey dengan cara mengambil semua jenis Anggur Laut yang ditemukan di setiap stasiun. Lokasi pengambilan sampel ditetapkan sebanyak tiga stasiun, yaitu Stasiun I, Stasiun II dan Stasiun III. Dalam 1 stasiun terdapat 3 transek kuadrat. Stasiun yang telah ditentukan akan diukur dengan transek kuadrat berukuran 1x1 meter (Ruswahyuni dan Widyorini, 2014). Selanjutnya memasang line transek dengan panjang disk, Penggaris, Roll meter, Transek kuadrat dan Bahan yang digunakan adalah Sampel Anggur Laut (Caulerpa sp.).

75 meter dari garis pantai menuju ke arah laut. Meletakkan transek kuadrat berukuran 1x1 meter yang didalamnya dibagi kedalam 16 kotak kecil dengan ukuran masing-masing $25 \mathrm{~cm}$ untuk memudahkan dalam perhitungan kerapatan Anggur Laut.

\section{Analisis Data \\ Parameter Kualitas Perairan}

Analisis parameter kualitas perairan menggunakan data deskriptif dan diolah dalam bentuk tabel untuk mengetahui nilai kualitas perairan.

\section{Identifikasi Jenis Anggur Laut}

Anggur laut yang sudah diambil sampelnya kemudian diamati untuk mengetahui bentuk talus. Identifikasi Anggur Laut dilakukan di Laboratorium Perikanan, Universitas Bengkulu dengan melihat ciri dari bentuk morfologi dengan menggunakan buku identifikasi rumput laut dari Setyobudiandi, I. $d k k$. (2009).

\section{Kerapatan Relatif Anggur Laut}

Perhitungan kerapatan relatif yaitu dengan mencatat semua jenis Anggur Laut dan masing-masing dalam bentuk individu dan menghitung kerapatan relatif setiap jenis dalam satu komunitas. Perhitungan menggunakan rumus Odum (1993) dalam Ruswahyuni (2014), yaitu kerapatan relatif (KR) jenis Anggur Laut: Metode ini dilakukan dengan cara mencatat seluruh jenis Anggur Laut dan menghitung 
Jurnal Perikanan (2020) Volume 10. No. 2 : 195-204

DOI : https://doi.org/10.29303/jp.v10i2.215

kerapatan relatif dengan rumus sebagai berikut:

Keterangan :

$\mathrm{KR}=$ Kerapatan relatif

$K R=\frac{\text { Jumlah individu jenis } A}{\text { Jumlah individu seluruh jenis }} \times 100 \%$

\section{HASIL}

Gambaran Umum Lokasi Penelitian

Lokasi penelitian terletak di

Pantai Teluk Sepang, Kecamatan
Sepang, Kota Bengkulu. Penelitian ini difokuskan pada satu wilayah yang terdiri dari tiga titik sampling yang terletak di pantai Teluk Sepang. Wilayah lokasi penelitian bisa dilihat pada Gambar 2. Kampung Melayu, Kelurahan Teluk

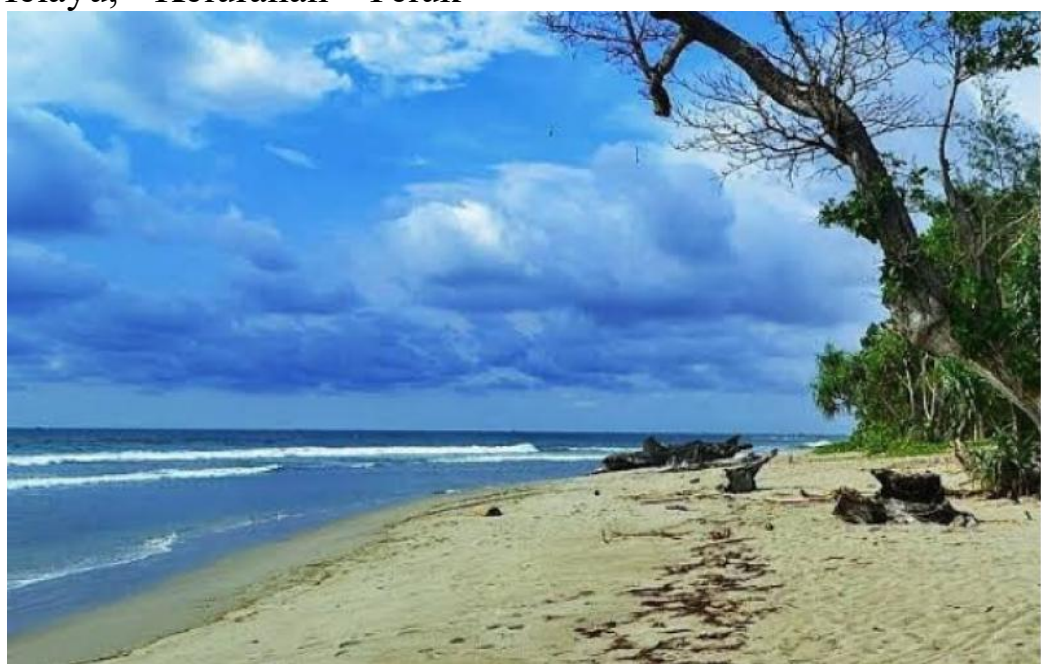

Gambar 2. Lokasi penelitian (Dokumentasi Pribadi)

Analisis Parameter Kualitas Perairan

Pengukuran parameter kualitas perairan yang berpengaruh terhadap pertumbuhan Anggur Laut yaitu suhu, salinitas, $\mathrm{pH}$ (derajat keasaman), dan kecerahan. Hasil pengukuran parameter kualitas perairan dapat dilihat pada Tabel 2.

Tabel 2. Parameter kualitas air di Pantai Teluk Sepang

\begin{tabular}{|c|c|c|}
\hline Parameter kualitas Air & Pengukuran kualitas air & Baku mutu \\
\hline Suhu $\left({ }^{\circ} \mathrm{C}\right)$ & $30-32$ & $24^{\circ}-36^{\circ} \mathrm{C}$ (Sulistidjo, 1986) \\
\hline Salinitas (ppt) & 32 & $\begin{array}{l}28-33 \% \text { ppt (Anggadiredja, } \\
d k k ., 2006)\end{array}$ \\
\hline $\mathrm{pH}$ & $7,7-7,8$ & 7,3-8,2 (Susanto $d k k ., 2001)$ \\
\hline Kecerahan $(\%)$ & 100 & \\
\hline $\begin{array}{l}\text { Suhu yang sesu } \\
\text { Laut yaitu dengan suhı } \\
\text { namun masih ditemuk }\end{array}$ & $\begin{array}{l}\text { k Anggur } \\
20-30^{\circ} \mathrm{C}, \\
\text { buh pada }\end{array}$ & $\begin{array}{l}\text { tur } 33^{\circ} \mathrm{C} \text { (Ismail dan Pratiwi, } \\
\text { Temperatur lingkungan berperan } \\
\text { dalam proses fotosintesis, } \\
\text { semakin tinggi intensitas }\end{array}$ \\
\hline
\end{tabular}


matahari dan semakin optimum kondisi temperatur, maka akan semakin sistematik hasil fotosintesisnya (Lee, 1999). Adapun suhu yang diperoleh pada saat penelitian yaitu $30-31^{\circ} \mathrm{C}$. Hal ini sesuai dengan pendapat Sulistidjo (1986) yang menyatakan Anggur Laut dapat tumbuh pada suhu antara $24^{\circ}$ $36^{\circ} \mathrm{C}$

Salinitas merupakan salah satu parameter kualitas air yang memegang peranan penting dalam memacu laju pertumbuhan biota yang dipelihara (Sulistijo, 1986). Salinitas yang diperoleh selama penelitian berkisar 30 32 ppt. Nilai salinitas ini sebenarnya cukup tinggi, akan tetapi di sisi lain salinitas tinggi dapat memacu nilai klorofil. Ini sesuai dengan pendapat Hui $d k k$., (2014), yang menyatakan salinitas tinggi dapat berpengaruh terhadap fotosintesis makroalga, alga akan menonaktifkan pusat reaksi fotosistem dan menghambat transfer elektron. Hal ini sesuai dengan pendapat Anggadiredja, $d k k$., (2006) yang menyatakan Anggur Laut dapat tumbuh dengan optimal pada salinitas antara 28$33 \%$ ppt.

Nilai pH dipengaruhi oleh beberapa faktor antara lain aktifitas biologi seperti fotosintesis dan respirasi organisme, temperatur, dan keberadaan ion-ion dalam perairan tersebut (Pescod, 1973). Adapun nilai $\mathrm{pH}$ yang diperoleh pada saat penelitian yaitu 7,7-7,8. Hal ini sesuai dengan pendapat Susanto (2001) yang menyatakan Anggur Laut dapat tumbuh dengan optimal pada $\mathrm{pH}$ 7,3-8,2.

Berdasarkan hasil pengukuran dapat diketahui bahwa kecerahan yang diperoleh selama penelitian yaitu berkisar antara 0,5-0,68 meter dan mencapai nilai optimum yaitu $100 \%$ dikarenakan kondisi perairan mencapai surut terendah dan sangat memungkinkan sinar matahari untuk dapat masuk hingga kedalam dasar perairan. Hal ini diperkuat oleh Sunarto (2009), yang menyatakan bahwa kecerahan pada kisaran sebesar 0,5 meter cukup mendukung untuk pertumbuhan optimal Anggur Laut.

\section{Identifikasi Spesies Anggur Laut}

Hasil identifikasi spesies Anggur Laut di Pantai Teluk Sepang ditemukan 3 spesies Anggur Laut, yaitu Caulerpa taxifolia, Caulerpa racemosa, dan Caulerpa lentillifera.

Caulerpa taxifolia di perairan Pantai Teluk Sepang (Gambar 3) ditemukan di daerah intertidal dan melekat pada substrat terumbu karang yang tergenang air laut. Menurut Industry and Investment NSW Government (2009) dalam Amanah dkk., (2014), Caulerpa taxifolia dapat ditemukan pada sebagian substrat termasuk batu, pasir, dan lumpur. 
Jurnal Perikanan (2020) Volume 10. No. 2 : 195-204

DOI : https://doi.org/10.29303/jp.v10i2.215

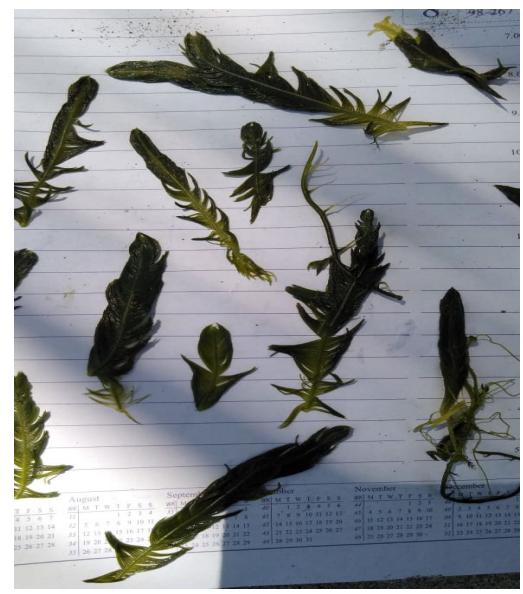

Gambar 3. Caulerpa taxifolia (Dokumentasi Pribadi)

Caulerpa taxifolia yang yang lebih dalam. Stolon terdapat ditemukan di Pantai Teluk Sepang rhizoid berukuran 1-3 cm, sedangkan memiliki ciri talus pipih memanjang seperti bulu-bulu mirip dengan daun pakis yang tumbuh mendatar dan tumbuh bercabang, berwarna hijau tua dan tumbuh tegak (asimilator), ukurannya bervariasi dari tinggi 10-20 $\mathrm{cm}$ dan lebar 7-10 cm. Diameter daun 6$8 \mathrm{~mm}$ dan panjang tangkai $3-15 \mathrm{~cm}$ di dangkal, sedangkan panjang tangkai pada assimilator terdapat daun yang mirip dengan bulu ayam atau daun pakis berwarna hijau tua berukuran 0,3-0,5 $\mathrm{cm}$.

Spesies Caulerpa racemosa di Pantai Teluk Sepang (Gambar 4) hidup menancap atau menempel di substrat dasar perairan laut seperti karang mati, fragmen karang, pasir, dan lumpur.

mampu mencapai 20-60 $\mathrm{cm}$ di perairan

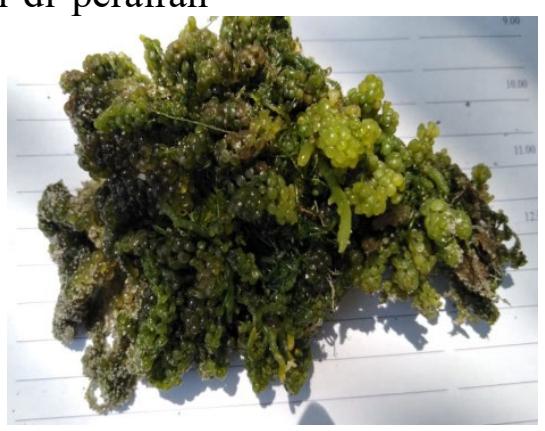

Gambar 4. Caulerpa racemosa (Dokumentasi Pribadi)

Caulerpa racemosa yang ditemukan di Pantai Teluk Sepang memiliki ciri talus berwarna hijau seperti tanaman rumput, terdiri dari banyak cabang tegak yang tingginya sekitar 2,5-6 cm. Batangnya berukuran antara 16-22 cm. Tumbuhan ini memiliki bulatan-bulatan seperti anggur pada puncak cabang, panjang setiap puncak cabang sekitar 2,5-10 cm. Berdasarkan beberapa penelitian yang telah dilakukan, Caulerpa racemosa menghasilkan metabolit sekunder yang berfungsi sebagai antioksidan (Ridhowati dan Asnani, 2016). Chew dkk., (2008) menyatakan bahwa 
Jurnal Perikanan (2020) Volume 10. No. 2 : 195-204

DOI : https://doi.org/10.29303/jp.v10i2.215

Caulerpa racemosa mampu menangkal radikal bebas karena jenis alga tersebut mengandung asam folat, tiamin, dan asam askorbat. Santoso dkk., (2002) menyatakan bahwa Caulerpa racemosa yang berasal dari Indonesia mengandung insoluble dietary fiber (IDF atau serat makanan tak larut air) yang sangat tinggi, bahkan lebih tinggi daripada rumput laut yang berasal dari Jepang. Menurut Astawan (2004), serat makanan tidak larut umumnya terdiri dari selulosa dan hemiselulosa yang berperan penting dalam mencegah kanker usus besar, sembelit dan ambeien.

Caulerpa lentillifera yang ditemukan di Pantai Teluk Sepang (Gambar 5) umumnya tumbuh pada daerah terumbuh karang, menempel pada substrat karang atau pasir pada kedalaman lebih dari 50 meter dan terkadang juga dapat ditemukan di perairan dangkal.

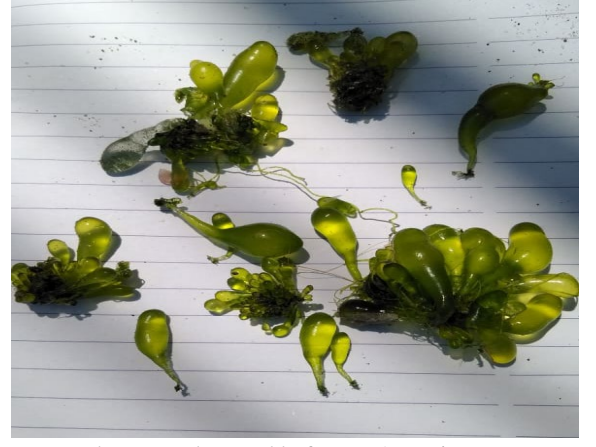

Gambar 5. Caulerpa lentillifera (Dokumentasi Pribadi)

Caulerpa lentillifera adalah salah satu spesies dari golongan alga hijau yang pada umumnya memiliki talus yang menyerupai buah anggur, berwarna hijau cerah, sedikit mengkilap, dan berstektur lembut. Tekstur Caulerpa lentillifera yang kenyal, berair, dan renyah membuat Anggur Laut ini dapat dimakan dan rasanya asin seperti air laut. Caulerpa lentillifera di Indonesia

\section{Analisis Kerapatan Relatif Anggur}

Laut

Tabel 3. Analisis Kerapatan relatif Caulerpa sp.

\begin{tabular}{llccccc}
\hline No. & Spesies & $\begin{array}{c}\text { Stasiun } \\
\text { I }\end{array}$ & $\begin{array}{c}\text { Stasiun } \\
\text { II }\end{array}$ & $\begin{array}{c}\text { Stasiun } \\
\text { III }\end{array}$ & $\begin{array}{c}\text { Jumlah } \\
\text { Individu }\end{array}$ & $\begin{array}{c}\text { Kerapatan } \\
\text { ind } / \mathrm{m}^{2}\end{array}$ \\
\hline 1. & Caulerpa taxifolia & 42 & 38 & 72 & 152 & 46,6 \\
2. & Caulerpa racemosa & 55 & 47 & 68 & 170 & 52,1 \\
3. & Caulerpa lentillifera & - & 4 & - & 4 & 1,2 \\
\hline
\end{tabular}

dimanfaatkan sebagai bahan makanan. Caulerpa lentillifera mayoritas ditemukan di Indonesia, Filipina, Thailand, Vietnam, Jepang, dan Papua Nugini. Selain itu juga terdistribusi di sepanjang Pantai Timur Afrika (Afrika Selatan, Mozambik, Madagascar, Tanzania, Kenya, Mauritius, Somalia) (Seaweed Industry Association, 2014).

Analisis kerapatan relatif Anggur Laut di Pantai Teluk Sepang bisa dilihat pada Tabel 3 . 
Jurnal Perikanan (2020) Volume 10. No. 2 : 195-204

DOI : https://doi.org/10.29303/jp.v10i2.215

Total

326

Jumlah individu Caulerpa sp. yang ditemukan pada masing-masing stasiun yaitu, stasiun I sebanyak 97 individu, stasiun II yaitu 89 individu, dan stasiun III yaitu sebanyak 140 individu. Spesies Caulerpa racemosa memiliki kerapatan relatif jenis paling tinggi yaitu dengan $52,1 \mathrm{ind} / \mathrm{m}^{2}$, hal ini dikarenakan spesies ini tumbuh pada substrat pasir dan pecahan karang mati yang mendominasi pada setiap stasiun yang ada pada lokasi penelitian di perairan pantai Teluk Sepang. Hal ini sesuai dengan pendapat Mubarak dan Wahyuni (1961), yang menyatakan bahwa jenis-jenis substrat yang dapat ditumbuhi oleh Caulerpa sp. adalah pasir dan pecahan karang mati.

Spesies Caulerpa taxifolia memiliki kerapatan relatif yaitu 46,6 ind $/ \mathrm{m}^{2}$, dan kerapatan relatif jenis terendah ada pada jenis Caulerpa lentillifera yaitu dengan $1,2 \mathrm{ind} / \mathrm{m}^{2}$. Pada lokasi penelitian, genus Caulerpa sp. banyak ditemukan pada perairan yang memiliki rataan terumbu karang yang habitatnya pada substrat mati, pasir, dan pecahan karang mati. Kebanyakan spesies ini tidak tahan pada kondisi kering, oleh sebab itu Caulerpa sp. tumbuh pada surut terendah yang masih tergenang air. Pada umumnya, makroalga Caulerpa sp. tumbuh bergerombol.

Nontji (1993) menyatakan bahwa sedikitnya Caulerpa sp. yang terdapat pada perairan dengan dasar pasir atau berlumpur, disebabkan karena terbatasnya benda keras yang cukup kokoh untuk tempat melekatnya. Susunan kimia dari substrat tidak mempengaruhi kehidupan alga laut, hanya sebagai tempat melekatnya alga laut, pada dasar perairan.

\section{KESIMPULAN}

Berdasarkan hasil penelitian didapatkan 3 spesies dan kerapatan relatif Anggur Laut (Caulerpa sp.) di Pantai Teluk Sepang Kota Bengkulu yaitu Caulerpa taxifolia $\left(46,6 \mathrm{ind} / \mathrm{m}^{2}\right)$, Caulerpa racemosa $\left(52,1 \mathrm{ind} / \mathrm{m}^{2}\right)$ dan Caulerpa lentillifera $\left(1,2 \mathrm{ind} / \mathrm{m}^{2}\right)$.

\section{DAFTAR PUSTAKA}

Amanah, I., A. M. Khiftiyah dan R. Y. Oxi. 2014. Analisis kandungan karbohidrat dan klorofil makroalga Caulerpa taxifolia dari Pantai Sokobanah, Madura. Jurusan Biologi. Fakultas Matematika dan Ilmu Pengetahuan Alam. Universitas Negeri Surabaya. Surabaya.

Anggadiredja, J. T., A. Zatnika, H. Purwoto, dan S. Istini. 2006. Rumput Laut. Penebar Swadaya. Jakarta.

Astawan, M. 2004. Seri Gaya Hidup Sehat SENIOR: Kandungan Gizi Aneka Bahan Makanan. Gramedia. Jakarta.

Chew, Y. L., Y. Y. Lim, M. Omar, K. S. Khoo. 2008. Antioxidant Activity of Three Edible Seaweeds from Two Areas in South East Asia. LWT. 41: 1067-1072.

Hui, G., Zhongmin S., Delin D. 2014. Effect of Salinity and Nutrient on the Growth and Chlorophill Fluorescence of Caulerpa lentillifera. Chinese Journal of Oceanology and Limnology, and Springer-Verlag Berlin Heidelberg. 
Jurnal Perikanan (2020) Volume 10. No. 2 : 195-204

DOI : https://doi.org/10.29303/jp.v10i2.215

Ismail, W. dan Pratiwi, E. 2002. Budidaya Laut Menurut Tipe Perairan. Warta Penelitian Perikanan Indonesia. Pusat Riset Perikanan Budidaya. Jakarta. 8 (2): $8-12$.

Kadi, A. 2000. Potensi Rumput Laut di Beberapa Perairan di Indonesia. Jurnal oseana. 29 (4): 25-36.

Lee, F. A. 1999. Basic Food Chemistry. The Avi Publishing Company, Inc., New York.

Mubarak, H. dan Wahyuni I. 1981. Percobaan Budidaya Rumput Laut di Perairan Lorok, Pacitan dan Kemungkinan Pengembangannya. Bull. Pen. Perikanan. I (2): 157166.

Nontji, A. 1993. Fotosintesis Pada Fitoplankton Laut. Tinjauan Fisiologi dan Ekologi. Fakultas Pasca Sarjana. Institut Pertanian Bogor (IPB). Bogor.

Pescod, M. B. 1973. Investigation of Rational Effluent and Sream Standard for Tropical Countries. Intern Research Report. ATT. Bangkok.

Ridhowati, S. dan Asnani. 2016. Potensi Anggur Laut Kelompok Caulerpa Racemosa Sebagai Kandidat Sumber Pangan Fungsional Indonesia. Jurnal Oseana. 41 (4): 50-62.

Ridhowati, S. dan Asnani. 2016. Potensi Anggur Laut Kelompok Caulerpa Racemosa Sebagai Kandidat Sumber Pangan Fungsional Indonesia. Jurnal Oseana. 41 (4): 50-62.

Ruswahyuni, N. A. dan Widyorini, N. 2014. Hubungan Kerapatan Rumput Laut Dengan Substrat Dasar Berbeda Di Perairan Pantai
Bandengan, Jepara. Diponegoro Journal Of Maquares. 3 (1): 99107.

Santoso, J., Y. Yoshie, dan T. Suzuki. 2002. The Distribution and Profile of Nutrient and Catechin of Some Indonesian Seaweed. Fisheries Sciences. 68: 1647-1648.

Seewed Industry Association. 2014. Caulerpa lentillifera (online). https://en.wikipedia.org/wiki/ Caulerpa_lentillifera.

Setyobudiandi I., Soekandarsi E., Juariah U., Bahtiar, dan Hari H. 2009. Rumput Laut Indonesia: Jenis dan Upaya Pemanfaatannya. 63 hal. Fakultas Ilmu Kelautan dan Perikanan. Universitas Haluoleo. Sulawesi Tenggara.

Suhartini, S. 2003. Penapisan Awal Caulerpa racemosa, Sesuvium portulacastrum, Xylocarpus granatum, dan Ulva lactuca Sebagai Antimikroba. Skripsi. Bogor: Program Studi Teknologi Hasil Perikanan. Fakultas Perikanan dan Ilmu Kelautan. Institut Pertanian Bogor.

Sulistijo. 1986. Penelitian Budidaya Rumput Laut (Algae Makro/Seaweed) di Indonesia. Pidato Pengukuhan Ahli Penelitian Utama Bidang Akuakultur, Pusat Penelitian Oseanografi. LIPI.

Sunarto. 2009. Pertumbuhan Gracilaria dengan Jarak Tanam Berbeda di Tambak. Jurnal Akuakultur Indonesia. 8 (2) : 157-16.

Susanto, H. 2001. Budidaya Ikan di Pekarangan. Penebar Swadaya. Jakarta.

Yangthong, M., Towatana, H., dan Phromkunthong, W. 2009. Antioxidant Activities of Four 
Jurnal Perikanan (2020) Volume 10. No. $2: 195-204$

DOI : https://doi.org/10.29303/jp.v10i2.215

Edible Seaweeds from the Southern Coast of Thailand. Plant Foods for Human Nutrition. 64 (3): 218-223. 